Bataller Català, A. (2020): Llegenda i paisatge com a elements de mediació literària Encantades i pedagogia de l'imaginari. Cultura, Lenguaje y

Representación, Vol. XXIII, 7-23

ISSN $1697-7750 \cdot$ e-ISSN $2340-4981$

DOI: http://dx.doi.org/10.6035/clr.2020.23.1

\title{
Llegenda i paisatge com a elements de mediació literària. Encantades i pedagogia de l'imaginari
}

Legend and landscape as elements of literary mediation. Fairies and pedagogy of the imaginary

AleXANDRe Bataller CATALÀ

UNIVERSITAT DE VALÈNCIA

Artículo recibido el / Article received: 2019-11-01

Artículo aceptado el / Article accepted: 2020-03-30

RESUM: S'hi analitzen les possibilitats de mediació literària que ofereix el paisatge llegendari a partir d'una experiència de ruta literària desenvolupada amb alumnes de primària en un espai natural on es vincula una llegenda (en concret, el Barranc de l'Encantada a Planes). El treball situa la relació entre llegenda, història i pensament científic i la distinció entre contes i llegendes en funció del seu caràcter meravellós o històric. Es tracten els conceptes de pensament màgic, imaginació i fantasia associada als infants, en el context d'una pedagogia de l'imaginari. Per a l'anàlisi i comprensió de la llegenda de l'Encantada, es contextualitzen els relats medievals on apareixen sirenes i dones aquàtiques, entre elles Melusina, i els relats posteriors que s'hi deriven. S'hi esmenten elements comuns i pervivències de versemblança $i$ historicitat en els relats orals sobre encantades valencianes. Finalment, s'hi aporten elements d'anàlisi de l'experiència concreta de recepció i creació literària de la llegenda, a partir del seguiment de la ruta literària i de l'entrevista amb el docent que ha dissenyat aquest dispositiu didàctic basat en elements de la literatura de transmissió oral associada a un territori

Paraules clau: llegendes, paisatge, fantasia, pensament màgic, encantades, pedagogia de l'imaginari, ruta literària, educació literària.

ABSTRACT: The possibilities of literary mediation of the legendary landscape are analyzed based on a literary experience developed with primary school students in a natural space where a legend is linked (in particular, Barranc de l'Encantada in Planes, Alicante). The work places the relationship between legend, history and scientific thought and the distinction between stories and legends based on their marvelous or historical nature. The concepts of magical thinking, imagination and fantasy associated with children are treated, in the context of a pedagogy of the imaginary. For the analysis and understanding of the Enchanted legend, contextualising the medieval tales where seals and aquatic women appear, including Melusina and the subsequent stories that come from it. Common elements and survival of credibility and historicity are mentioned in the 
oral stories about Valencian fairies. Finally, elements of analysis of the concrete reception and literary creation of the legend are provided, based on the follow-up of the literary route and the interview with the teacher who has designed the best didactic device based on elements of literature of oral transmission associated to a territory.

Key words: legends, landscape, fantasy, magical thinking, fairies, pedagogy of the imaginary, literary routes, literary education.

\section{LA LLEGENDA I EL PENSAMENT MÀGIC}

\subsection{EL MITE FRONT AL PENSAMENT CIENTÍFIC}

A partir de la Il·lustració, el món erudit occidental separà el mite de la història; des d'aleshores els historiadors desestimen el mite dels registres històrics en percebre'l com un discurs fals. Aquesta vella qüestió ha donat peu a nous replantejaments. L'historiador nord-americà Peter Heehs considera que la història moltes vegades es converteix en una mena de mite, que el discurs científic també s'empra quan s'inventa una tradició, ja que la ciència és «el nostre mite cultural prevalent» (Heehs, 1994: 11). Per Heehs, l'avantatge del mite sobre la història és que «crea una versió del passat que és més significativa per a molta gent que un acoblament crític de fets» (Heehs, 1994: 18).

Enfront de la idea que el discurs científic supera el mític, ja que tots dos són producte d'un mateix tipus de pensament, el folklorista rus Eleazar Meletinski els considerà discursos diferents:

La ciencia no puede, como esperaban los positivistas del siglo XIX, borrar completamente la mitología; ante todo porque la ciencia no resuelve problemas metafísicos generales, como el sentido de la vida, el objetivo de la historia, el misterio de la muerte etc., pero la mitología sí pretende resolverlos.

(Meletinski, 2006: 34)

L'antropòleg David Bidney va definir el pensament mític com «una creença, generalment expressada en forma narrativa, que és incompatible amb el coneixement científic» i que es refereix a «nocions i relats que un cop acceptats i creguts no mereixen una creença racional» (Bidney, 1950: 23). Per a aquest antropòleg el mite no mor amb l'arribada de la Il·lustració i és, per tant, una forma de pensament difícil d'erradicar de la ment humana. Avisava contra la tendència a concebre el mite com «una forma més alta de veritat» i aconsellava que es combatera el pensament mític amb el científic i el crític. Per la seua part, el filòsof Rubin Gotesky va reaccionar contra aquesta visió de Bidney tot assenyalant les incongruències del seu pensament $\mathrm{i}$ adduint que «el mite, com qualsevol altra creença, pot ser fals, però no és fals per ser un mite» (Gotesky, 1952: 13). Segons Gotesky, el que un mite siga acceptable o no per a una cultura no depén de criteris científics, sinó de les necessitats i interessos individuals i col-lectius. Els mites transcendeixen tot criteri científic de veritat; serveixen com a postulats a sistemes socials; s'accepten per la seua utilitat social i perquè són molt significatius per a la societat i els seus membres. Aquest filòsof és de l'opinió que una societat regida uniformement per la ciència rebutjarà els mites que contradiguen l'experiència i la raó científica (Gotesky, 1952: 531). 


\subsection{LA LLEGENDA I EL MITE COM A «HISTÒRIES VERTADERES»}

Per a l'historiador Mircea Eliade (1999: 151) la civilització occidental està formada per la suma de la cultura, un univers religiós dessacralitzat i una mitologia desmitificada, que manifesten el triomf del logos enfront del mythos i la victòria del llibre sobre la tradició oral, del document escrit per sobre una experiència viscuda que només disposava d'uns mitjans d'expressió preliterària. Assenyala Eliade (1999: 16) que, en les societats en què el mite és encara viu, els indígenes (com ara la tribu ameríndia pawnee) distingeixen els mites («històries vertaderes») de les rondalles o contes, que anomenen «històries falses».

El folklorista i antropòleg nord-americà William R. Bascom (1965) va fer servir una combinació d'elements formals i actitudinals per elaborar una taula de característiques definitòries dels tipus de relats folklòrics. Entre els criteris diferenciadors inclou en primer lloc la creença (que distingeix entre fet i ficció), seguits de l'actitud cap al relat (si es considera sagrat, profà o si inclou les dues categories), el temps (si l'acció passa en un passat remot, històric o és indiferent), el lloc (si s'esdevé en un món diferent, en el món segons el coneixem o si no importa) i els personatges principals (si són humans, no humans o si apareixen totes dues categories).

El folklorista William Hansen (2002) ha assenyalat que la principal discriminació de gènere per als relats orals tradicionals està entre les narracions que clarament es presenten com fictícies i el seu propòsit és entretenir o servir d'exemple i les que es conceben com històries tradicionals sobre esdeveniments del passat històric. A aquesta dicotomia, que separa el conte de la llegenda, s'afegeix un tercer gènere que tracta sobre la formació i establiment del cosmos i els esdeveniments d'un passat remot: els mites.

Entre les definicions de llegenda considerem la de Carme Oriol (2001: 105) que remarca que aquesta «es construeix sobre una base real, i per això és percebuda com un relat creïble, però el seu component extraordinari l'allunya d'altres relats pròpiament realistes com són les anècdotes o les històries sobre experiències reals»». La definició de Luis Díaz (2008: 146) arreplega de forma succinta els trets característics d'una llegenda: una narración fuertemente localizada, personificada en protagonistas que pueden o no ser históricos, pero que casi siempre se mueven en una esfera de cierta temporalidad, y con una aspiración de verosimilitud o credibilidad, a pesar de que -con frecuencia- trate de hechos o acciones bastante sorprendentes.

\subsection{LA DISTINCIÓ ENTRE EL REAL I L’IMAGINARI EN ELS CONTES PER A INFANTS}

Almenys des dels postulats de Bruno Bettelheim (2012: 171), hi ha el consens a considerar que els contes de fades estimulen la fantasia dels infants. Durant els primers anys de vida l'infant no fa una distinció clara entre real i imaginari. Des d'infantil fins a segon de primària, molts infants pensen que la realitat del conte coexisteix amb la seua realitat imaginària (Guérette i Roberge-Blanchet, 2003: 44). Serà més endavant quan l'infant començarà a diferenciar entre el real, com allò possible, i l'imaginari, com a allò no possible

Però el nen no pot entrar en la imaginació fins que no té accés al món racional. El món real és molt dur per a un nen i és per això que fuig de la realitat. Aquesta fuga és crucial per al nen $i$, en aquest sentit, la màgia dels contes respon bé a aquesta necessitat. De fet, un nen creurà més fàcilment una explicació aportada per un conte, fantàstica per tant, que no una explicació real proporcionada pels pares perquè no és capaç d'entendre aquesta última. La imaginació del conte permet així al nen alliberar-se de les seues 
pressions internes. Aquesta necessitat de «somnis» és servida per l'element meravellós dels contes. Els contes tracten temes de la vida però de forma simbòlica, per fer pensar al nen. Així, el conte utilitza un llenguatge simbòlic que cal desxifrar. Aquest desxiframent permet 1'apropiació personal. Com assenyala Bettelheim (2012: 103-104): «El niño comprende, intuitivamente, que aunque estas historias sean irreales, no son falsas, que aunque lo que estos relatos nos dicen no ocurra en realidad, tiene que pasar como experiencia interna y desarrollo personal».

Per a la psicoanalista alemanya Marie-Louise Von Frantz, deixebla de Jung, els contes de fades expressen de forma molt directa les processos psíquics de l'inconscient col·lectiu.

Dans les mythes, les légendes ou dans tout autre matériel mythologique plus élaboré, l'on n'atteint les structures de base de la psyché humaine qu'à travers une couche d'éléments culturels qui les recouvre. Les contes de fées, par contre, contiennent bien moins de matériel culturel conscient spécifique, aussi reflètent-ils avec plus de clarté les structures psychiques fondamentales.

(Franz, 1995: 12)

La llegenda comparteix amb la història el fet de ser, sobretot, una història amb caràcter meravellós. No obstant això, amb el pas del temps es va produir una diferenciació: les llegendes es localitzen i s'associen a un fet històric, mentre que els contes no fan referència a cap realitat precisa i per això es difonen amb més facilitat. Com va assenyalar Bettelheim (2012: 421 n. 34): «No suele ser corriente que en los cuentos de hadas se citen nombres propios de lugares determinados». Com afirma el psicoanalista austríac, un dels objectius dels contes de fades és donar confiança al nen. Una similitud massa gran amb el que viu l'inquietaria encara més, en comptes de tranquil·litzar-lo. És per això que el conte de fades deixa entendre des del començament de la intriga que no ens parla de fets tangibles, ni de persones o llocs reals. Aquesta imprecisió intencionada indica que deixem el món concret i la realitat quotidiana. Així, la història no se situa en l'espai i en el temps sinó, més aviat, en la «realitat interior del nen».

\subsection{DEL PENSAMENT MÀGIC A LA PEDAGOGIA DE L'IMAGINARI}

Julio Caro Baroja entén el «pensament màgic» dins la tradició antropològica de Frazer i Malinowski, que el defineixen com un procés mental essencialment irracional que consisteix a atribuir efectes a causes sense haver entre ells una correlació de causalitat científicament demostrable. En concret, afirma que «la mentalidad mágica es en sí una forma de pensamiento del hombre (y de la mujer) que no es la religiosa, ni la científica, ni la artística» (Caro Baroja, 1987: 10).

El «pensament màgic» dels infants és, també, un concepte utilitzat en psicologia. Designa una etapa compresa entre els $2 \mathrm{i}$ els 7 anys. Aquesta edat de l'imaginari donarà pas a l'edat de la raó (com es manifesta en les creences dels Reis mags o el Pare Noel). La psicoanalista francesa Sophie Morgenstern (1934: 102) localitza el pensament màgic en tots els països i pobles, en la neurosi, en el pensament infantil i en el somni i, com a punt en comú, assenyala l'element afectiu i el llenguatge del somni. L'infant cerca en el món màgic una realització que li aporte una satisfacció immediata i completa («Rien n'empêche l'enfant de vivre dans ce monde magique à côté de la vie réelle», Morgenstern, 1934: 103), perquè la vida dels adults representa un món misteriós màgic en el qual ell voldria penetrar i apropiar-se.

En nom d'una cientificitat, d'un esperit enciclopedista i d'una educació que privilegiara l'aprenentatge de la racionalitat, molts pedagogs del segle XIX bandejaren la imaginació. Per aquesta raó ha calgut una reivindicació de les capacitats creadores de la 
imaginació des d'àmbits educatius. Georges Jean (1976) concep una «pedagogia de l'imaginari»: «Elle se voudrait un entrainement dynamique a la perception et a la conscience du réel par toutes les facultés de l'être lui permettant de ne pas limiter ses relations au monde à la perception immédiate qu'il en a» (Jean, 1976: 28). L'infant té necessitat de ficció per construir-se i somiar el seu avenir, raó per la qual cal desenvolupar i nodrir la seua imaginació. L'imaginari permet aprehendre el món, aporta una interpretació subjectiva, tributària de la nostra experiència de la vida i del medi (cultural, social i familiar) d'on procedim i ens permet pair l'experiència humana.

\subsection{LA REIVINDICACIÓ DE LA FANTASIA}

El teòric de la literatura Tzvetan Todorov va assenyalar que el fantàstic i el meravellós tenen llocs comuns i una distinció que qualifica de fugaç, el fenomen fantàstic, escriu, «ne dure que le temps d'une hésitation» (Todorov, 1976: 46). En aquest context: «Ce qui distingue le conte de fées est une certaine écriture, non le statut du surnaturel» (Todorov, 1976: 59).

Per la seua banda, el romanista Pierre Castex (1971) oposa el fantàstic al meravellós. Per a ell el meravellós implica un estranyament de l'esperit. L'oient, el lector d'un conte meravellós, seria transportat a un altre espai, a un altre temps indeterminat. Le «pouvoir des contes» est bien dans les déplacements par lesquels nous avons l'illusion de vivre pour un court instant «hors du temps» et «ailleurs» (Jean, 1981: 60-61). L'humanista Pierre M. Schuhl (1969) demostra que en cada art, en cada ciència, en cada tècnica, en tota història, en cada pas de la ment, individual o col·lectiu, la raó reuneix la imaginació i el seu producte inevitable, el meravellós: «dans les fantastique, la possibilité d'explication rationnelle doit toujours y accompagner le mystère de l'interprétation naturelle» (Schuhl, 1969: 9).

El pedagog Gabriel Janer Manila va saber copsar - i difondre en un moment molt oportú per a la renovació pedagògica - el valor educatiu de la fantasia present a les rondalles, en una unió complementària de racionalitat i imaginació:

No és la fantasia un refugi al marge de la realitat, sinó una mirada diversa —o divergentsobre la realitat, una forma de proposta alternativa, el risc de jugar la carta de l'insòlit. Una energia que transforma la realitat, l'enriqueix, la depura. Les rondalles m'ensenyaren, també, com és possible entremesclar amb els gestos quotidians, amb la vida de cada dia, l'experiència extraordinària. Molt de temps després, he comprès que és inútil contraposar-los, el pensament racional i la imaginació, car no s'oposen cegament ni es contradiuen, sinó que constitueixen el camí a través del qual els homes avancen i progressen.

(Janer Manila, 1989: 63)

L'esperit científic no hauria de desaconsellar, en cap cas, la reivindicació de la fantasia, com destaca l'escriptor Víctor Montoya:

...ningún maestro, por muy experimentado o excelente que fuese, está autorizado a coartar la fantasía de los alumnos por el simple capricho de hacer de sus lecciones una cátedra destinada a impartir conocimientos técnicos y científicos en detrimento de las facultades creativas y emocionales del niño.

(Montoya, 2001: 8)

De tota manera, en el cas de les llegendes, hi hauria veus discrepants. El professor Jaume Albero, per exemple, considera les llegendes adequades dins el context de l'educació literària dels adolescents, però entén que hi ha elements i valors constitutius en elles (com ara el pacte amb el Diable, l'aparició de sers del més enllà, les històries de 
bruixes, etc.) que podrien generar en el xiquet una incertesa $i$ un sentiment d'inseguretat respecte al seu entorn. Per aquesta raó desaconsella l'ús de les llegendes abans de l'adolescència: «desaconsejamos vivamente el uso pedagógico de estas historias en los jóvenes de menor edad» (Albero, 2005: 15).

\section{L'UNIVERS LLEGENDARI MEDIEVAL DE LES DONES AQUÀTIQUES}

\subsection{LES SIRENES EN L'IMAGINARI MEDIEVAL}

La primera referència escrita a les dones aquàtiques la trobem en el cant XII de l'Odissea, quan es narra l'episodi en què Ulisses, instruït per Circe, va tapar amb cera les orelles dels seus mariners i es va fer lligar al pal de la seua embarcació per poder escoltar els seus cants sense sucumbir davant elles. Mentre que el mite de la dona aquàtica significa mort en Homer, per al cristianisme és símbol de perdició, perfídia o ruïna moral per a qui cau en els enganys de la seducció femenina. Aquestes sirenes a poc a poc van perdre el seu caràcter malèfic per a passar a simbolitzar l'aspiració de l'home per penetrar en allò obscur o desconegut $\mathrm{i}$ anar més enllà de les seues forces normals

El principal atractiu de la sirena el constituïa el seu seductor cant d'amor que exercia sobre qui l'escoltava una atracció fatal. Va nàixer com a símbol dels perills que comporta l'abisme marítim, però en l'Edat Mitjana es va associar a la luxúria, la temptació $i$ els perills que encarna la sexualitat, perquè aquestes dones aquàtiques eren éssers volàtils com l'amor, a més d'encarnar la falsedat, l'engany i la inconstància. La sirena és un ésser híbrid amb cap de dona i cos d'au en el cas de les sirenes-ocell. Però també pot tenir el cos d'una dona que des de la cintura es metamorfosa en peix rematant en una aleta.

La sirena és present al bestiari medieval català (Martín, 2009: 133-137). En concret, un text de primeries del segle XIV diferencia tres classes de sirenes (segons el component animal siga peix, ocell o cavall) i les considera uns éssers que enganyen els homes:

La serena sí és una creatura molt meravellosa, e ha-n'i de tres maneres: la una és mig peix e mig fembra, l'altra és mig oçel e mig fembra, e l'altra és mig cavall e mig fembra. Aquella qui és feta axí com a peix e fembra, sí ha tan dolsa veu que tot hom qui la hoja cantar s'i acosta volenter per hoyr-la, e plau-li tant la veu del seu cant que s'i adorm; e quant la serena veu que l'om és adormit, ve-li dessús e alciu-lo. [...] Aquestes serenes podem nós acomparar a les fembres qui [no] són de bona conversació, qui enganen los hòmens, los quals se anamoren d'elles, o per bellesa de cors, o per ullades que elles los fan, o per paraules enginyoses que elles diguen, o en altra manera. E en qualsevol manera que ella engan a l'ome, ell se pot tenir per mort.

(Panunzio, 1963: 79)

Per la seua banda, el Llibre del Tresor, traducció catalana de l'obra enciclopèdica en francès escrita pel notari florentí Brunetto Latini (s. XIII), estableix una classificació segons la seua corporeïtat siga la d'un peix i ocell, una flauta o una cítola, per atraure els homes amb els seus cants, tractades com a tres meretrius:

Sereynes, ço dien los actors, són de iii maneres: la huna qui ha semblança de dona del cap tro a les cuxes, mas d'allí en avall ha semblança de peix, e han ales e ungles e canta meravellosament; l'altre, de flauta e de canó, la iiia de cítola; qui per lut dolç cant fayen perir los no sabents qui anaven per mar. Mas la veritat, les serenes foren iii àvols fembres qui enganaven tots los trespassants e-ls amtien en pobretat.

(Wittlin, 1976: 45) 


\subsection{LA TRADICIÓ DELS RELATS MELUSÍNICS}

Melusina, la més famosa de les fades del feudalisme, dotada de poders sobrenaturals, havia estat condemnada per la seua mare, la fada Presina, a metamorfosarse en dona-serp tots els dissabtes, en una font de cristal-lines aigües de Poitiers $i$, naturalment, havia de tenir cura que ningú la descobrís, sota l'amenaça de patir el paradoxal càstig de la immortalitat. Quan el seu marit humà va incomplir la promesa que li havia fet de no espiar-la durant el seu bany ella va recuperar la seua forma de dona-serp i va fugir del Castell de Lusignan. Però a la nit, en sentir els crits dels seus fills, tornava per donar-los de mamar.

Els clergues veien en ella una diablessa, però no així els cavallers, que la consideraven una fada protectora i maternal: «tan sólo eran demonios súcubos en la cultura eclesiástica; pero tanto para los milites como para los campesinos, al menos algunas de ellas eran buenas madres, madrinas generosas o amantes solícitas, aunque imprevisibles y celosas» (Schmitt, 1992: 102-103). Fins i tot, Rabelais se'n fa ressò de la versemblança d'aquestes dones amb cos de botifarra i aporta l'argument d'alguns coetanis seus que jurarien pel braç de sant Rigomer haver vist Melusina:

Si estas explicaciones no satisfacen la incredulidad de vuestras señorías, visitad ahora mismo (quiero decir, después de echar un trago) Lusignan, Parthenay, Vouvent [vouvant], Mervernt y Pouzanges en Poitou. Allí encontraréis testigos, viejos de buena fama y bien templados, que os jurarán sobre los brazos de san Rigomé que Melusina, su primera fundadora, tenía cuerpo femenino hasta la bolsa de las vergas y que el resto hacia abajo era butifarra serpentina o serpiente butifárrica.

(Rabelais, 2011: 1095-1096)

A més, el personatge llegendari de Melusina va ser emprat per a justificar l'ascendència mítica de diversos llinatges:

diversos llinatges cavallerescos de l'Anjou i del Poitou prengueren model del folklore per a les llegendes dels seus orígens sobrenaturals i l'explicació mítica de la seva fortuna a partir del segle XII: els Lusignan i els mateixos Plantagenêt, afirmaven que descendien de la fada serpent Melusina, a la qual devien, els uns la corona de Xipre i els altres la d'Anglaterra.

(Schmitt, 1986: 26)

Entre els segles XII i XIII veuran la llum un seguit de relats genealògics que segueixen l'anomenat «conte melusinià» en el qual un ser sobrenatural s'uneix a un mortal i li concedeix el seu amor a canvi de la promesa de respectar una prohibició: la transgressió d'aquesta provoca la desaparició del ser superior. Les dames amants del bosc són presentades, a partir del segle XII, com a fades: entitats sobrenaturals que també posseeixen les característiques que la cultura clàssica va atribuir a les Parques i a les nimfes.

Xulio Pardo de Neyra (2015) veu en les dones d'aigua de la tradició llegendària -des de la Melusina de Jean d'Arràs, passant per l'Ondina del baró de Fouqué, fins arribar a la Marinha gallega- la crida de la dona donadora i segadora de vida que des del Paleolític els homes identifiquen amb la suprema senyora dels destins humans. Sirenes que provoquen i invoquen l'home, en una crida telúrica divina. Com explica el folklorista Luis Díaz: «Estamos tratando con seres extranaturales, con mujeres que gozan de los hombres y causan su muerte o intentan provocársela. Viven en cuevas o fuentes. Vienen de otro tiempo o -mejor- nos hablan de otros tiempos. Y ésta es la clave». (Díaz, 2008: 160). 


\section{LES LLEGENDES D'ENCANTADES}

\subsection{DONES D’AIGUA O ENCANTADES CATALANES PIRINENQUES}

El concepte de «dona d'aigua» fa referència als éssers femenins que apareixen a la vora de l'aigua, molt relacionats amb fonts o llacs (diferenciats de les «sirenes», éssers marins). El mot més general és «fada», present en la majoria d'idiomes europeus, però no tant al folklore català. «Encantada» és molt difós també en la toponímia. «Goja», i en menor mesura «aloja», són mots emprats per Verdaguer. I «jana» és present també als topònims (Roviró, Roviró i Ayats, 1987: 124-125).

Les encantades catalanes s'estenen principalment pel Pirineu: «es pot considerar que aquest tipus llegendari apareix localitzat principalment al Pirineu, Pre-pirineu i Montseny» (Violant, 2002: 10). Les tradicions d'encantades o d'éssers diabòlics al cim del Canigó són antiquíssimes i han estat citades per testimonis diversos, entre els quals Eiximenis, al Primer del Crestià o Gervasius von Tilbury, al segle XIII (Hauf, 1988). Les encantades presents al poema Canigó (1886) de Jacint Verdaguer han estat estudiades des del punt de vista de la tradició oral catalana (Roviró, Roviró i Ayats, 1987).

La seducció de les encantades acostuma a concretar-se la nit de Sant Joan. En algun cas, es produeix el casament entre un humà i una encantada, com el que se situa a l'estany de Lanós, a l'Alta Cerdanya:

A l'estany de Lanós hi viuen dones d'aigua que encanten en la nit de Sant Joan tothom qui s'hi acosti. La reina de les dones d'aigua s'enamora d'un jove d'Enveig. Es volien casar i li prometé felicitat eterna. Anaren a viure al palau de les dones d'aigua però el marit tenia prohibit girar-se pel camí. En sentir bèsties estranyes que udolen, es gira. Les bèsties es convertiren en pedra $i$ ell també.

(Amades, 1950: 134-135)

En la tradició oral, les encantades viuen sempre en coves o balmes, a sota terra $\mathrm{i}$ ben sovint prop de l'aigua. El palau que hi ha dins l'estany de Canigó és descrit per l'escuder a Gentil com «un castell que qui hi va no en torna». La cova on habiten unes altres encantades és també una cova amb cent corredors i llums de colors. Jacint Verdaguer descriu les encantades de la Cambra de les Encantades, vora el camí de Coll d'Ares a Prats de Molló: «En altre temps diu que hi vivien les encantades, donzelles no batejades, molt hermoses, que sols sortien de nit; i si sortien de dia, se feien abans invisibles» (Verdaguer, 2002: 34).

\subsection{LES ENCANTADES VALENCIANES}

Francesc Gisbert (2008: 79-94) reconeix encantades en sirenes o velletes misterioses. El professor alteà Joan Borja (2014: 96-103), en el seu complet repertori sobre el cicle narratiu de les encantades valencianes, destaca les morisques, belles guardianes de tresors. Hi aporta, al respecte, un variat «inventari d'urgència»:

«La Joanaina, a Teulada», «Castell de Segart (Camp de Morvedre)», «El castell del Bou Negre, a Argeleta», «Bou d'or, a la cova de l'Àguila, a Xodos», «La pedra encantada de Montesa», «L'encantada del Cabeço Soler», «Les Columbretes», «El barranc de l'Encantada, a Planes», «La dama encantada del castell de Milleneta», «La cova del Lladre, a les Canyades d'en Cirus, de Monòver», «L'escala de la donzella, a Moixent», «L'encantada de la Giraba a Lludient», «La penya del Benicadell, a Beniarrés» i «Pere Joan i la princesa encantada a la cova o mina d'Ocre, a l'Albir».

(Borja, 2014: 98) 
A aquesta relació hi afegeix l'encantada del castell de Penella i la del castell de Travadell, a més de la llegenda de la Reina Mora («les reines mores són veritables encantades que ostenten els atributs de la riquesa i bellesa; i que habiten literàriament la fantasia de castells i paratges relacionats amb l'aigua», Borja, 2014: 100), localitzada al castell de l'Alfàndec o de Marinyén, a Benifairó de la Valldigna i als Banys de la reina de Calp i el Campello i al Clot de la reina a Moraira.

Per a escatir la qüestió de la historicitat de la llegenda entre els guardians de la memòria oral, ens detindrem especialment en el cas de l'encantada del Cabeço Soler, un turonet situat entre Guardamar i Rojals, recollida per Serra i Román del Cerro (1986: 120-157). Deixant de banda l'esquema de la llegenda, que s'esdevé cada nit de sant Joan, amb l'aparició d'una encantada que custodia un tresor en una cova, tal com es conta d'un veí (el tio Vila) que s'enfrontà a un bou i rebé com a càstig la maledicció d'anar tota la vida amb la llengua fora, ens interessa el component de fet verídic associat a la llegenda, viu encara entre els habitants més majors de la contrada:

En Rojales, el «tío Jesús», al que todo el pueblo nos remitió como el mejor conocedor de cuentos y leyendas, estuvo largo rato contando historias, trovos, relaciones, etc. Y, curiosamente, no contó la leyenda de La Encantá. A la vista de ello, se le pidió que nos relatara esta leyenda, a lo que respondió: «Pero eso no es un cuento, eso es historia». Y, efectivamente, todo el pueblo la tiene por verdadera e incluso, les incomoda hablar de ello.

(Serra i Román del Cerro, 1986: 175)

Els mateixos investigadors reporten una situació semblant esdevinguda a Rojals, l'any 1984, davant un expert local en regs:

Al fondo destacaba el cabecico Soler. Al entrar en el pueblo estábamos un poco rezagados los dos junto a un par de alumnos. Y le abordé claramente: ¿«Podría contarme usted la Leyenda de la Encantá?» Me miró muy sorprendido. Algunas personas se cruzaban con nosotros por la acera. Lo vimos turbado. Empezó a contar algo, pero se paraba, siempre en voz baja y mirando a su alrededor como quien quiere que no se le descubra. No hubo forma de que contara nada. Una vez en el autobús, y fuera de miradas indiscretas, me la narró muy sucintamente. Y al final dijo: «En estas historias, ¿dónde está el cuento y dónde la verdad?». Realmente me impresionó lo viva que perdura la leyenda, no porque sea vivo el recuerdo, sino porque la narración se confunde con la realidad, con la creencia.

(Serra i Román del Cerro, 1986: 175-176)

En una altra presència d'encantada valenciana, a la llegenda de l'Encantada de Gandia, es descriu una dona vaporosa, «com transparent, coberta a la manera mora, amb peus de pota de cabra», que vigila les pertinences $i$ els tresors que els àrabs van deixar abandonats després de la conquesta cristiana de Bairén, a l'Ullal Fosc, ben a prop d'on es registra la llegenda de l'enfonsament de Gandia, que també està revestida per un cert grau d'historicitat, segons els informants:

...el que ja estranya més és que avui dia, amb un nivell d'instrucció bàsica generalitzat a la nostra societat, certes llegendes es prenguen per fets realment ocorreguts o, almenys, s'hi dubte. Les informadores que ens contaven la llegenda de l'esfondrament de Gandia a 1'Ullal Fosc, on està enterrada, quan ho narraven afirmaven: «diuen...» No creien ni deixaven de creure en la historicitat dels fets narrats.

(Bataller Calderón, 1999: 209)

\subsection{LA LLEGENDA DE L'ENCANTAMENT DE PLANES}

Possiblement, la llegenda valenciana més coneguda protagonitzada per una encantada és la que, com ens recorda la toponímia, designa el barranc de l'Encantada, al 
terme de Planes, a la comarca del Comtat. Una donzella encantada (una morisca en bona part de les versions, però també una dona aquàtica en unes altres), abillada amb una diadema d'or pur que llu sota els raigs de sol cada vegada que fa un eixida cada cent anys es trobarà amb un llaurador que treballa els camps veïns al barranc. Quan el té davant li farà la pregunta clau: quina de les dues coses prefereix quedar-se, la cora d'or o a ella mateixa. Si el llaurador opta per la corona queda de manifest que és un avariciós i cobdiciós de riqueses i allà mateix li dona mort. Si la tria a ella, els portarà a la seua cova i es quedarà encantat de per vida. Faça el que faça, desapareixerà. El protagonista, en alguna versió, és un moliner:

Diuen que un moliner, de camí al seu molí, que s'havia construït per aprofitar la força de l'aigua del barranc una mica abans que el cabal anara a enfortir el corrent del Serpis, s'aturà a l'altura del gorg del Salt perquè li semblà escoltar una veu dolça i encisadora que el cridava pel seu nom...

(Capó, 2002: 51)

L'escriptor Víctor Labrado literaturitza la versió de la musulmana com «La reina mora» i recrea l'espai del palau secret com a habitatge de l'encantada:

En un gran cau foradat dins la muntanya té, tot per a ella, un palau secret fet de molts passadissos i cambres, on viu i no viu, senyora i presonera del seu tresor. Tant si camina com si reposa, la foscor li encega sempre els ulls i en la buidor només sent els degotissos de les coves.

(Labrado, 2007: 101)

Bernat Capó (2002: 49-55) diferencia dues versions bàsiques, segons siga una sirena o una bella musulmana l'encarregada de custodiar el fabulós tresor. En la versió de la sirena l'opció consisteix a «Triar entre fer-me teua, amb la qual cosa es desfarà l'encantament, o agafar aquesta diadema que porte al cap, que forma part d'un gran tresor que roman amagat a l'interior d'aquesta pedra, que és com una gran porta màgica». (Capó, 2002: 52). En la versió de la musulmana la demanda és semblant: «Has de triar entre aquesta pinteta d'or que porte al cap, que és una petita mostra del tresor que es troba a l'interior de la muntanya, sota la vigilància de les àguiles que fan niu a la Penya Roja, 0 fer-me teua aquí mateix, després de nadar pel gorg». (Capó, 2002: 52).

La referència a la llegenda de l'Encantada de Planes que fa Antoni Cavanilles el 1797, connectada amb l'expulsió dels moriscos, expressa a les clares la visió d'un il·lustrat que situa la llegenda en el territori de la ignorància i la indignació racional:

....aprovechar las aguas. Van cayendo estas al barranco que la ignorancia y la credulidad llamó de la Encantada por la piedra circular de unos cinco pies de diámetro, que en forma de ventana cerrada se ve en la garganta del barranco á 20 pies sobre el nivel ordinario de las aguas. En esta fingió el vulgo la boca de cierta mina, donde los Moros escondieron sus tesoros, y dexáron encantada una doncella, que cada 100 años sale para volver á entrar en el mismo día. Fábulas indignas de hombres juiciosos, perpetuadas solamente por la superstición é ignorancia.

(Cavanilles, 1797: 153)

Per la seua banda, l'historiador alacantí Francisco Figueras Pacheco coincideix amb la idea del tresor amagat dels moriscos $\mathrm{i}$ es fa ressò de la mina on hi és, però no descarta, com seria esperable d'un esperit racional, el poder màgic de l'encantament:

Cruza igualmente el término el barranco de la Encantada, que procede de Alcalá de la Jovada y desemboca en el Serpis por los campos de Beniarrés. Recibe su nombre, este barranco, de una mina que supone existe junto a él, donde los moros escondieron sus tesoros, y dejaron encantada a una doncella, que sale una vez cada cien años para volver a entrar el mismo día. Una losa aproximadamente circular de metro y medio de diámetro, 
aparece en el estrecho del barranco, cerrando el supuesto subterráneo. Hace diez o doce años (hacia 1900) se intentó volar con pólvora aquella puerta de roca, para descubrir lo que hubiere tras ella, pero no se consiguió arrancarla, ya porque el encantamiento es muy grande, ya tal vez porque la cantidad de pólvora fue pequeña.

(Figueras Pacheco, 1919: 802-803)

Joan Borja (2019: 63) situa aquesta mina en el paratge de l'Estret, enfront del Molí Mató o Molí de l'Encantada, i recorda que pels anys vint del segle passat es dinamità la roca per comprovar-ne l'existència de tresors (vegeu també Capó, 2002: 55).

\section{L’ACCÉS A LA LLEGENDA PER MITJÀ DEL PAISATGE}

\subsection{EL PAISATGE COM A ELEMENT MEDIADOR EN EDUCACIÓ LITERÀRIA}

Tot i que la promoció del treball de camp i la relació amb l'entorn és a la base dels moviments de renovació pedagògica, l'educació en paisatge pren volada amb el Conveni Europeu del Paisatge (CEP) de l'any 2000, del qual es deriven pràctiques d'aplicació amb infants (Castiglioni, 2009). Podem entendre el paisatge com un producte social que genera sentiments de pertinença i apropiació de l'espai per a les col·lectivitats humanes. Per a identificar-nos amb l'entorn, per a conèixer-lo, interpretar-lo i construir-nos-hi com a individus, cal sentir el patrimoni. S'imposa la tasca educativa de despertar sentiments $\mathrm{i}$ emocions en els espais més propers. Una educació que contemple la dimensió patrimonial del paisatge afavorirà el sentit de lloc, l'adquisició del concepte de temps històric i el desenvolupament de vincles positius de l'alumnat amb l'entorn (Busquet, 2010).

El paisatge és susceptible de l'emoció, fins al punt d'arribar al que ha estat anomenat «èxtasi paisatgística». El paisatge pot esdevenir font de sorpresa, d'atracció pel seu genius loci, del qual en fan part contes i llegendes:

Mais tout a commencé peut-étre le jour de notre premier apprentissage de l'espace, lorsque, enfant, on nous faisait découvrir le monde auquel nous appartenions a travers une promenade, la vue de la chambre, et cette grande et merveilleuse fenêtre ouverte sur l'univers et la vie que sont les contes. [...] La force des contes, comme des légendes les plus fantastiques, est de s'appuyer sur des phénomenes et une nature puissants, pour les recouvrir de féerie. Les forêts sont mystérieuses, les lacs enchantés, les mers infinies, les lieux se chargent de connotations fantastiques.

(Scariati i Bailly, 1989: 23)

En el món contemporani, amb un context de transformació i adaptació de la literatura popular preindustrial a uns nous usos i necessitats, la càrrega social, simbòlica i comunicativa dels textos transmesos per la tradició oral és una altra diferent a la del seu origen, en un procés que ha estat definit com a «transcontextualització» (Pujol, 2013: 32). La funció del docent, en l'àmbit de l'educació literària, té a veure amb la seua funció mediadora:

Las funciones del profesor de literatura se organizan entre su rol de mediador de saberes sobre las producciones literarias, su función de intérprete y crítico de los textos, su función de mediador en la exposición de metodologías de análisis y las funciones docentes, que se consideran esenciales, de formador y de estimulador o animador de lectores.

(Mendoza, 2002: 120)

La promoció dels espais i llocs literaris, com a instruments de mediació literària, ens aboca a «una concepció de la literatura basada en l'experimentació, un acostament a la literatura per la via del territori i de l'emoció» (Bataller, 2016: 203). Els elements de 
literacitat presents en la geografia literària es combinen amb la possibilitat de percebre l'emoció estètica en llocs concrets (Bataller i Reyes, 2019). N'és representatiu el treball de mediació lectora a partir de llegendes relacionades amb la geografia navarresa de López i Aisáin (2017), que inclou la mediació patrimonial, la comprensió i interpretació, l'estímul a la creativitat i l'animació a la lectura. Des de l'experiència personal amb la implementació d'itineraris pel territori llegendari mallorquí, que ajuden a fer de la literatura una experiència intensament viscuda, Caterina Valriu assenyala que «L'objectiu general és donar a conèixer el territori i la literatura oral que s'hi relaciona, tot establint una simbiosi enriquidora culturalment» (Valriu, 2018: 91).

\subsection{UNA EXPERIÈNCIA DE RUTA LLEGENDÀRIA AL BARRANC DE L'ENCANTADA AMB ALUMNES DE PRIMÀRIA}

El Centre de Recursos per a l'Ensenyament (CRA) «L'Encantada» agrupa els aularis d'Alqueria d'Asnar, Benimarfull i Planes, és a dir, una escola repartida en tres poblacions diferents i separada entre elles per deu quilòmetres, dins la comarca del Comtat. Un punt bàsic de la identitat de CRA és adaptar les actuacions educatives al medi, a fi d'assolir un major coneixement de la realitat sociocultural i mediambiental de la comarca. El CRA va decidir l'apadrinament del «Barranc de l'Encantada», amb l'ús de la transversalitat d'aquest espai natural, històric i llegendari dins el currículum (García i Caballer, 2008).

El mestre Carlos Caballer inclou, des de fa més d'una dècada, la llegenda de l'Encantada dins la seua planificació educativa. Aprofita, per als seus interessos, la versió de l'autor local Miquel Gadea (Miquel d'Elena, 1886-1966), que posa en relació una bella dona i un llenyater:

Segons el conte relata, / i la veritat pot ser / una senyora molt guapa / li va eixir a un llenyater. / Li ensenyà un collar de plata / amb un diamant i un robí, / «Què és el que vols, la joia? / O m’estimes més a mí?» / Va contestar que la joia. / «Sempre seràs desgraciat! / En aquella penya alta / tinc un palau encantat. / Ja no podràs ser ditxòs; / si m'hagueres volgut a mí, / la fortuna que hi ha allí / haguera sigut p'als dos». / Per mig d'una boreal, / a l'amanèixer l'aurora, / desapareix la senyora / i es queda el pobre... igual. / Si es que la dita els agrada, / no se la prenguen per falòria / que és l'origen de la Història / del Barranc de l'Encantada.

(https://ajuntamentdeplanes.es/web_ajuplanes/html//legenda.php)

El procés de transposició didàctica que opera aquest mestre en la realització de la ruta literària ha estat estudiat per Federico Fojas (2017: 53-59), el qual destaca dues claus que determinen l'exercici de la seua professió: la capacitat d'implicar-se personalment en un projecte pedagògic i la capacitat d'adaptar-se a l'entorn i a la comunitat escolar.

Del seguiment, com a observador participant, de la ruta literària efectuada el 14 d'abril de $2017 \mathrm{amb}$ un grup de nou alumnes del primer cicle de primària percebérem la fascinació i l'atracció pel meravellós dins el context d'un paisatge i com el docent permetia als infants decidir sobre la pròpia llegenda, convertida en una història d'amor entre un llaurador i una princesa. Convindríem a acceptar que se segueixen els principis de Maria Montessori en relació al fet que no es prou amb contar els contes per desenvolupar les possibilitats de la imaginació (Montessori, 1986: 320).

L'itinerari proposat es basteix sobre el paisatge, esdevingut el correlat d'una narració llegendària que ha estat consensuada amb els infants:

El Toll del Gorg és el més important perquè situem ací el castell del pare de la donzella. Comencem la narració. Després passe a buscar altres tolls més xicotets caminant pel barranc assenyalant que serien les piscines naturals on aniria la donzella a banyar-se per 
les nits i en alguns dels pins que estan a la vora s'amagaria el personatge que s'enamora d'ella per la seua bellesa. Els corralets enderrocats que resten serien la vivenda de l'enamorat de la donzella i els bancals dels voltants serien la seua horta i el lloc on pasturava el su xicotet ramat. Hi ha un corralet que encara mostra al barranc un xicotet assut on dona més realitat al lloc on vivia aquest personatge i que utilitzava l'aigua per regar la seua horta. Per finalitzar, arribem al Toll de l'Estret al costat de l'antic molí on vivia el bruixot que amb els seus beuratges, per encàrrec del rei, encanten la donzella.

(Caballer, comunicació personal, 21/08/2019)

En concret, es reinterpreta l'espai amb l'ús d'uns objectes (la corda i les claus), que tenen la funció d'apropar el món real i el màgic:

Està present sempre el sentiment de si seran rebuts per la donzella per ser el moment especial de la seua eixida cada cent anys i així ser els privilegiats de poder desencantarla. Pensen a portar les cordes a la motxilla per tirar-la a liaigua del Toll del Gorg i veure si passa alguna cosa. preparem el moment $i$ arribem a la vora del Toll amb silenci per llançar la corda a l'aigua. En altres moments també arribem a portar manolls de claus antigues per veure si alguna entra en els imaginaris panys que podem trobar a la penya per poder obrir la porta del palau.

(Caballer, comunicació personal, 18/08/2019)

El pensament màgic es materialitza sobre el paisatge. El palau imaginari, la porta $i$ el pany que cal obrir amb les claus són percebuts i diferenciats pels infants:

Baix de la penya del Toll del Gorg, el més gran i emblemàtic, hi ha un trosset que té un altre color i que mirant-lo de lluny sembla la forma d'una porta. Xiquets i xiquetes veuen realment la porta. Busquen on podria estar el pany i amb les claus antigues que portem tracten i proven a vore si puguera obrir-se la porta del palau. He viscut escenes on els xiquets tenen por d'estacar la clau en un forat, per si per casualitat puguera obrir-se la porta que ells estan veient. Són moments fantàstics i irrepetibles.

(Caballer, comunicació personal, 21/08/2019)

Finalment, el mestre Carlos Caballer corrobora, amb la seua experiència personal, la pervivència del pensament màgic més enllà dels set anys:

El pensament màgic és indescriptible en Infantil i Primer cicle. Les emocions, les pors, la imaginació i la connexió és total a cada racó de la passejada. Un sorollet a l'aigua, un peixet, una granota, un pardalet que canta o que vola, el vent i el seu soroll entre els xops i pins o una floreta... alerten tots els seus racons de la imaginació. Crec que en tota la primària no arriba a perdre's aquest sentiment, sols al tercer cicle comencen les preguntes reals o amb segona intenció. Però, aquest últim curs he tingut la sort d'anar amb xiquets i xiquetes de Rotglà i Corberà i del CRA d'Otos que ens van visitar i puc dir que el sentiment màgic del paratge els engul. Els $i$ les de Rotglà eren de $4 \mathrm{t}$ de primària $\mathrm{i}$ el seu respecte i atenció va ser espectacular, amb un silenci teatral, a l'escoltar la narració de la llegenda a diferents indrets del paratge.

(Caballer, comunicació personal, 18/08/2019)

\section{CONCLUSIONS}

La utilitat social dels mites en la societat contemporània és un fet constatat que no hauria d'entrar en contradicció amb els principis del coneixement científic. Els usos de la literatura popular obeeixen a motivacions diferents de les que els justificaren en el origen, però la seua càrrega simbòlica i patrimonial ha de tenir, al món actual, el seu espai en els contextos socials i educatius. En concret, el conte meravellós, necessari per al creixement dels infants, entra de ple en el programa lector dels infants, atés que no presenta les 
concrecions espacials ni temporals que sí que trobem a la llegenda, considerada a totes les cultures com una «història vertadera».

L'anomenat pensament màgic és, alhora, una etapa en l'evolució dels infants $\mathrm{i}$ també una qualitat humana. Tot i que des de la Il·lustració, la cientificitat bandejà la imaginació com un element educatiu, els pedagogs contemporanis reivindiquen l'aplicació d'una pedagogia de l'imaginari al mateix temps que destaquen el valor educatiu de la fantasia present als contes populars.

Dins de la tradició llegendària, l'existència de les dones d'aigua és antiquíssima. De les connotacions negatives de les sirenes presents a l'Odissea fins als éssers que enganyen els homes de la tradició cristiana medieval es passà a un model representat per la fada Melusina que, per al món feudal, podia ser una mare o amant envejable. Al capdavall, es constata la presència d'uns éssers sobrenaturals femenins que viuen en coves o fonts i que ens parlen d'uns altres temps, que poden fer gaudir els homes però també provocar-los la mort.

En la tradició catalana, les dones d'aigua es localitzen al llarg del Pirineu i són objecte de múltiples llegendes, des de seduccions esdevingudes la nit de sant Joan fins a episodis de casaments amb humans. Entre les encantades valencianes, que podríem quantificar en més d'una quinzena, destaquen les morisques guardianes de tresors, a les quals afegiríem la Reina Mora. Els informants d'aquests relats els consideren una realitat històrica, com ocorre, per exemple, amb l'«Encantà» del Cabeço Soler a Rojals (actualment, per cert, un ritual folkloritzat, promogut des de la municipalitat per a celebrar la nit de Sant Joan). El mateix s'esdevé amb l'Encantada del barranc que du el seu nom a Planes, de la qual ja Figueras Pacheco considerava molt seriosament que «el encantamiento es muy grande».

L'existència d'una narració llegendària associada a un espai natural és, com hem exposat al llarg del present treball, la materialització del pensament màgic sobre el paisatge. El CRA «L'Encantada» de Planes empra transversalment aquesta llegenda dins el currículum de primària. En concret, el mestre Carlos Caballer integra la llegenda dins un projecte de reivindicació del relat mític en connexió amb l'espai, amb la realització d'itineraris didàctics i rutes literàries. La investigació efectuada amb el seguiment de l'operació de transposició didàctica de la llegenda dins el context escolar efectuada per aquest docent ens aproxima a la fascinació exercida per la literatura popular vinculada a un paisatge entre els joves aprenents. L'experiència ens confirma que la possibilitat d'experimentar l'emoció estètica en els espais, a partir de referents literaris llegendaris, pot esdevenir un poderós recurs didàctic. L'espai, el patrimoni natural i paisatgístic, pot actuar, doncs, com a element mediador i com a font d'emoció, amb la seua capacitat d'evocar l'altre patrimoni, l'immaterial, procedent de la tradició oral.

Tota mediació cultural consisteix a despertar el desig, a donar els mitjans per a accedir a pràctiques culturals i artístiques en tots els àmbits. A facilitar l'accés a la cultura mitjançant la implementació d'accions específiques cap a un públic determinat. En el cas de l'experiència descrita és el docent qui exerceix de mediador entre la literatura de tradició oral i un públic destinatari constituït per infants, que viuen en un territori pròxim. La seua funció és la d'enllaç. Amb la seua intervenció, recontextualitza la literatura sobre un paisatge. El paisatge esdevé un element imprescindible en la mediació que enllaça la llegenda, entesa com a memòria oral i mítica, a un públic que interpreta l'espai. La naturalesa històrica i llegendària d'un lloc concret incita el visitant a considerar-lo com a revelador d'una realitat històrica. Tota aquesta operació construeix significativament coneixement $\mathrm{i}$ aconsegueix, al capdavall, una sensibilització sobre els relats que conformen la memòria col·lectiva d'un poble i d'un territori. 


\section{REFERÈNCIES BIBLIOGRÀFIQUES}

Albero, Jaume. 2005. «El valor educativo de los cuentos populares». En $V$ Congreso Internacional Virtual de Educación. Buenos Aires: Universidad Nacional de La Plata, pp. 1-16.

Amades, Joan. 1950. Costumari català, vol. I. Barcelona: Selecta.

Bascom, William. 1965. «The Forms of Folklore: Prose Narratives». The Journal of American Folklore, 307: 3-20.

Bataller Calderón, Josep. 1999. Les rondalles valencianes. Gandia: CEIC Alfons el Vell.

Bataller, Alexandre. 2016. «Espais i llocs literaris, conceptes de mediació literària: aplicació al casos de C. Sánchez-Cutillas i M. Vicent». eHumanista/IVITRA, 10: 188-207.

Bataller, Alexandre i Agustín Reyes. 2019. «La pedagogía de las multiliteracidades y la experiencia estética como elementos clave en la enseñanza y el aprendizaje de lenguas. Por la consolidación de un paradigma». Revista Nebrija de Lingüística aplicada a la enseñanza de Lenguas, 13, 26: 13-30.

Bettelheim, Bruno. 2012. Psicoanálisis de los cuentos de hadas. Barcelona: Crítica.

Bidney, David. 1950. «The Concept of Myth and the Problem of Psychocultural Evolution». American Anthropologist, 52 (1): 16-26.

Borja, Joan. 2014. «L'expulsió dels moriscos en l'imaginari popular valencià». eHumanista/IVITRA 6: 74-107.

—. 2019. «L' Encantada de Planes». Información. 11.05.2019: 62-63.

Busquet, Jaume. 2010. «La educación en paisaje: una oportunidad para la escuela». Iber. Didáctica de las Ciencias Sociales, Geografía e Historia, 65: 7-16.

Capó, Bernat. 2002. Terra de cireres. Picanya: Bullent.

Caro Baroja, Julio. 1987. Magia y brujería: variación sobre el mismo tema. San Sebastián: Txertoa.

Castiglioni, Benedetta. 2009. Education on landscape for children. Estrasburg: Cultural Heritage, Landscape and Spatial Planning Division. Council of Europe.

Castex, Pierre-Georges. 1971. Le Conte fantastique en France, de Nodier à Maupassant. Paris: Jose Corti.

Cavanilles, Antoni J. 1797. Observaciones sobre la Historia Natural, Geografia, Agricultura, Población y Frutos del Reino de Valencia, vol. II. Madrid: Imprenta Real.

Díaz, Luis. 2008. «Amantes que se desvanecen en el tiempo: la memoria etnográfica o la compleja significación de las leyendas». Revista de Antropología Social, 17: 141164.

Eliade, Mircea. 1999. Mito y realidad. Barcelona: Kairós.

Figueras Pacheco, Francisco. 1919. «Provincia de Alicante». En Geografía general del Reino de Valencia, dir. F. Carreras y Candi. Barcelona: Alberto Martín.

Fojas, Federico. 2017. La transposición didáctica en las rutas literarias. Treball Fi de Màster, Màster d'Investigació en Didàctiques Específiques. València: Universitat de València.

Franz, Marie-Louise von. 1995. L'Interprétation des contes de fées. Paris: A. Michel.

García Doménec, María José i Carlos Caballer. 2008. "Un paratge natural com a eix transversal». Escola Catalana, 446: 34-36.

Gisbert, Francesc. 2008. Màgia per a un poble. Picanya: Bullent.

Gotesky, Rubin. 1952. «The Nature of Myth and Society». American Anthropologist, 54, (4): 523-531. 
Guérette, Charlotte i Sylvie Roberge-Blanchet. 2003. Vivre le conte dans sa classe. Montréal: Hurtubise HMH.

Hansen, William. 2002. Ariadne's Thread: A Guide to International Tales Found in Classical Litterature. London: Cornell University Press.

Hauf, Albert. 1988. «La seducció de Gentil en el "Canigó" de Verdaguer i el romanç de "El infante Arnaldos"». Caplletra. Revista Internacional de Filologia, 5: 73-97.

Heehs, Peter. 1994. «Myth, History and Theory». History and Theory, 33, (1): 1-19.

Janer Manila, Gabriel. 1989. Escola i cultura, el territori com a projecte. Barcelona: Edicions 62.

Jean, Georges. 1976. Pour une pédagogie de l'imaginaire. Paris: Casterman.

—. 1981. Le pouvoir des contes. Tournai: Casterman.

Labrado, Víctor G. 2007. Llegendes valencianes: criatures mítiques de la tradició oral. Alzira: Bromera.

López Flamarique, Maite i Alfredo Asiáin. 2017. «Una propuesta de mediación de cuentos y leyendas de Navarra realizada por alumnado de los Grados en Maestro en Infantil y Primaria». En Patrimonio y Creatividad. Miradas Educativas, ed. Ricardo de la Fuente i Carlos Munilla. Valladolid: Verdelís, pp. 373-386.

Martín, Llúcia. 2009. "Aquatic animals in the Catalan Bestiari». Reinardus, 21: 124-143. Meletinski, Eleazar M. 2006. «El mito y el siglo veinte», Entretextos. Revista Electrónica Semestral de Estudios Semióticos de la Cultura, 8: 34-40.

Mendoza, Antonio. 2002. «Las funciones del profesor de literatura bases para la innovación». En Aspectos didácticos de lengua y literatura, 12, ed. Belén Muñoz et al. Zaragoza: Publicaciones ICE. Universidad de Zaragoza, pp. 109-140.

Montessori, Maria. 1986. La mente absorbente del niño. México: Association Montessori International.

Montoya, Víctor. 2001. «El poder de la fantasía y la literatura infantil». Sincronía, 4: 1-9 [http://sincronia.cucsh.udg.mx/litinfant.htm]

Morgenstern, Sophie. 1934. "La Pensée magique chez l'enfant». Revue Française de Psychanalyse, VII, 1: 99-115.

Oriol, Carme. 2001. «Les llegendes de tresors als Països Catalans: un estudi comparatiu». En Arxiu de tradicions de l'Alguer, ed. Joan Armangué. Barcelona: Publicacions de l'Abadia de Montserrat, pp. 105-116.

Panunzio, Saverio. 1963-64. Bestiaris, 2 vols., col. «Els Nostres Clàssics». Barcelona: Barcino.

Pardo de Neyra, Xulio. 2015. Literatura de sereas: a maxia da muller acuática desde a literatura comparada. Noia [A Coruña]: Toxosoutos.

Pujol, Josep M. 2013. Això era i no era. Obra folklòrica de Josep M. Pujol. ed. Carme Oriol i Emili Samper. Tarragona: Publicacions de la URV.

Rabelais, François. 2011. Gargantúa y Pantagruel, trad. Gabriel Hormaechea. Barcelona: Acantilado.

Roviró, Xevi, Ignasi Roviró i Jaume Ayats. 1987. «Les encantades a "Canigó”», Anuari Verdaguer, 2: 119-131.

Scariati, Renato i Antoine S. Bailly. 1989. «Voyages, contes et genius loci», Espace géographique, 18, (1): 21-24.

Schmitt, Jean-Claude. 1986. El món imaginari i el món meravellós a l'edat mitjana. Barcelona: Fundació Caixa de Pensions.

—. 1992. Historia de la superstición. Barcelona: Crítica.

Schuhl, Pierre-Maxime. 1969. L'imagination et le Merveilleux. Paris: Flammarion.

Serra, M. Carmen i Juan Luis Román del Cerro. 1986. Leyendas de la Vega Baja. Alacant: Universitat d'Alacant. 
Todorov, Tzvetan. 1976. Introduction à la littérature fantastique. Paris: Éditions du Seuil.

Valriu, Caterina. 2018. «Itineraris de llegenda: una proposta activa per descobrir la simbiosi entre territori i literatura oral». Revista d'Etnologia de Catalunya, 41: $88-98$.

Verdaguer, Jacint. 2002. Del Canigó a l'Aneto. Edició comentada i il-lustrada de les llibretes d'excursió de 1882 i 1883, ed. Narcís Garolera i Curt Wittllin. Lleida: Pagès Editors.

Violant, Ramona. 2002. El món màgic de les fades. Sant Vicenç de Castellet: Farell.

Wittlin, Curt J. 1976. Brunetto Latini, El Libre del Tresor, col. «Els Nostres Clàssics». Barcelona: Barcino. 